\title{
Hybrid Regimes within Democracies Fiscal federalism and Subnational rentier states
}

\section{Carlos Gervasoni}

Cambridge, Cambridge University Press, 2018, 289 páginas.

\section{Sofía Vidotto}

«Todavía queda mucho por hacer». Podría ser la frase de un novato, pero fue parte del último slogan de campaña de quien gobierna la provincia de Formosa desde hace más de 20 años. Y aunque no todos corren con la misma suerte que Gildo Insfrán, no es inusual encontrar gobernadores en varias provincias argentinas que de una $u$ otra forma-logran desafiar los límites de la democracia. De hecho, la existencia de un régimen subnacional de dudoso tinte democrático no es una particularidad de Formosa. Tampoco de Argentina. Desde el trabajo seminal de O’Donnell, los especialistas coinciden en que el avance desigual de la democracia en el territorio trasciende las fronteras de América Latina.

«Hybrid Regimes within Democracies» representa uno de los esfuerzos más importantes de esta literatura por caracterizar y explicar la existencia de regímenes no democráticos en contextos nacionales que sí lo son, partiendo de la experiencia argentina para ofrecer herramientas -tanto analíticas como metodológicas- que permiten mirar más allá del caso.

La primera parte del libro propone un análisis minucioso y exhaustivo de la variable dependiente de interés: el nivel de democracia en las provincias argentinas. En el Capítulo 1, Gervasoni utiliza el concepto de democracia liberal representativa para definir y caracterizar aquellos regímenes provinciales que combi- nan «instituciones democráticas que, no son una mera fachada, con prácticas autoritarias» (p.30), a los que denomina híbridos. Consciente de los desafíos que supone trabajar con regímenes de esta naturaleza a escala local, los capítulos siguientes reflejan la preocupación recurrente del autor a lo largo del libro por capturar la variación territorial de la democracia con indicadores válidos y confiables. Inspirado en la literatura que analiza el fenómeno a nivel nacional, Gervasoni propone dos estrategias de medición alternativas: el Índice de Democracia Subnacional (SDI) (Capítulo 2) y la Encuesta de Expertos en Política Provincial (SEPP) (Capítulo 3). El primero trabaja con evidencia cuantitativa para determinar el nivel de democracia subnacional en Argentina en función del grado de oposición al ejecutivo y legislativo provinciales y la medida en que existen límites reales al poder del gobernador. Los hallazgos resultan especialmente relevantes, en tanto no solo demuestran que existen distintos niveles de democracia en las provincias argentinas -algo quizás esperable- sino que muchas de ellas se volvieron menos democráticas con el tiempo. La Encuesta de Expertos representa una estrategia de medición complementaria de naturaleza subjetiva. Este recurso novedoso demuestra la utilidad de recurrir a la opinión de expertos locales para capturar la complejidad de ciertas prácticas locales que la evidencia cuantitativa no captura. 
La segunda parte del volumen analiza posibles explicaciones detrás de la distribución desigual de la democracia en Argentina. El Capítulo 4 ubica el argumento del autor dentro de dos discusiones teóricas más generales. Por un lado, la clásica distinción entre explicaciones estructurales y de agencia, que caracteriza a esta literatura. Por otro lado, en la discusión sobre teorías fiscales y rentísticas de la democracia en las que se apoya su argumento. En ambos casos, la propuesta del autor resulta innovadora tanto por el tipo de explicación que propone que combina elementos de estructura y agencia- como por la variable independiente principal que toma de la literatura sobre regímenes nacionales y logra adaptar exitosamente al caso de estudio: las rentas fiscales. El Capítulo 5 desarrolla el argumento principal del libro, que da cuenta de que las provincias argentinas que más se benefician de la distribución fiscal de recursos, son las menos democráticas o -en términos de Gervasoni- las que mejor responden a su definición de regímenes híbridos. Esto ocurre porque la distribución de transferencias fiscales termina beneficiando a aquellas provincias menos densamente pobladas por encima del resto, poniendo a disposición de sus gobernadores un excedente de recursos conceptual y causalmente similar a las rentas petroleras que les permite mantener el control político en su provincia. En el Capítulo 6, Gervasoni somete su argumento a diferentes test estadísticos y demuestra que su hipótesis sobrevive aun cuando se consideran diferentes medidas de las variables independiente de interés y se controla por explicaciones alternativas. Más aún, el autor ofrece evidencia cualitativa de las poco democráticas La Rioja, San Luis, Santa Cruz, Santiago del Es- tero y Catamarca que verifican el mecanismo causal que sostiene su argumento principal: el rol económico predominante que alcanza el estado provincial genera una fuerte dependencia económica de los ciudadanos, las empresas y los medios de comunicación, y consecuentemente un control político sin precedentes por parte de quienes gobiernan la provincia.

La tercera parte del libro coloca el análisis de Argentina en perspectiva comparada. El último capítulo propone una medida alternativa de democracia subnacional el Índice de Democracia Subnacional Comparado- que el autor testea en siete democracias federales (Alemania, Argentina, Australia, Canadá, India, Estados Unidos y México) y una unitaria (Uruguay). La construcción del índice supone dos logros especialmente importantes para la incorporación de fenómenos de índole local al acervo de la política comparada. Por un lado, su composición lo vuelve una medida objetiva, confiable y poco demandante en términos de datos, lo que permite replicarla con relativa facilidad en múltiples contextos. Por otro lado, constituye una herramienta sin precedentes para comparar regímenes subnacionales entre diferentes países en distintos períodos de tiempo. Esto implica, que su definición y sus indicadores son capaces de viajar en tiempo y espacio, y que, al hacerlo, es posible extender el análisis más allá de los países federales -e incluso de los autoritarismos competitivos como Rusia- con los que típicamente trabaja esta literatura.

De esta forma, el volumen constituye una contribución fundamental por varios motivos. En primer lugar, aporta claridad conceptual sobre un tipo de régimen específico que está lejos de ser un autoritarismo puro pero que sigue 
siendo un desafío para la democracia. En segundo lugar, ofrece una rigurosa operacionalización del nivel de democracia, que combina de manera inédita indicadores alternativos para dar cuenta de lo que ocurre en Argentina y extenderlo a otras partes del mundo. En tercer lugar, dialoga con diferentes enfoques para construir una sólida explicación de por qué algunos líderes provinciales tienen más libertad que otros para recurrir a prácticas poco democráticas casi sin intervención del gobierno central.

Aunque las virtudes del trabajo son muchas, también se identifican algunas debilidades. Como menciona el propio autor, la relación entre rentas fiscales y nivel de democracia está mediada por la capacidad de agencia de los gobernadores. Esto significa que aunque la estructura juega un rol central en su argumento, hay provincias como Tierra del Fuego que reciben un gran volumen de rentas pero califican como democráticas. Aun cuando parte de esta anomalía es explicada por los modelos teóricos y estadísticos en términos del elevado ingreso per cápita de la provincia Austral, ésta permanece como un caso desviado. Lo que determina que un gobernador que dispone de este excedente de recursos decida y logre explotarlo a su favor parece estar asociado a sus objetivos, habilidades y otros recursos personales. Ahora bien, la evidencia cualitativa da cuenta extensamente de por qué es el caso en provincias muy poco democráticas como La Rioja o San Luis, pero no analiza qué ocurre en un caso como Tierra del Fuego, cuyo abordaje como caso negativo sin duda con- tribuiría a aumentar el poder explicativo de su argumento. En relación con este punto, si bien su teoría tiene un fuerte componente estructural, el rol que ocupa la agencia humana en su explicación demanda un análisis más exhaustivo sobre el perfil de los gobernadores. Dicho de otra forma, comprender las trayectorias previas o ciertas características particulares permitiría establecer si existe algún patrón común entre quienes logran apropiarse de estos recursos naturales y explotarlos exitosamente a su favor, y quienes deciden no hacerlo. En cualquier caso, un análisis teórico (o incluso estadístico) de estas variables resultaría de gran utilidad para comprender aun con mayor precisión la compleja relación que establece el autor entre las rentas fiscales y el nivel de democracia en las provincias argentinas.

Las conclusiones a las que llega Gervasoni confirman que seguimos atravesando un momento central en términos de variación democrática subnacional. Al menos en la Argentina, el nivel de democracia de las provincias no parece haber mejorado desde el retorno a la democracia sino más bien lo contrario. Y aunque es demasiado pronto para saber si esta tendencia se mantendrá en el tiempo, sin dudas será necesario seguir de cerca lo que ocurre "por debajo» de la política nacional y en este sentido, el libro resulta una lectura obligatoria para entender por qué algunos líderes provinciales logran controlar la política local prácticamente sin limitaciones mientras que otros tienen que conformarse con obedecer las reglas del juego. 